REVISTA X, Curitiba, volume 14, n.6,p. 143-156, 2019.

\title{
ENTRE SONHOS E DEVANEIOS: O ESPAÇO COMO COMPONENTE FUNDAMENTAL NAS NARRATIVAS FANTÁSTICAS
}

Between Dreams and Dances: Space as a Key Component in Fantastic Narratives

\author{
Lívia Maria Rosa SOARES (IFMA/UERN) ${ }^{1}$ \\ Antônia Marly Moura da SILVA (UERN) ${ }^{2}$
}

\begin{abstract}
RESUMO: Este artigo objetiva analisar a importância do espaço na construção de sentidos na narrativa fantástica, tomando como exemplo o conto Onírico de Caio Fernando Abreu. A partir da análise desse conto, podemos ver como o autor transporta para o seu texto questões que afetam o sujeito pós-moderno, especialmente as relacionadas às relações humanas muitas vezes marcadas por laços frágeis e inconsistentes. Dessa forma, nesta narrativa, o fantástico e o insólito atuam para representar a realidade cotidiana em relação ao imaginário e ao inconsciente. Nosso suporte teórico será desenvolvido a partir das ideias de Roas (2012), Ceserani (2006), Bessière (2012), Gama-Khalil (2012), Borges Filho (2007), Brandão (2013), entre outros.
\end{abstract}

PALAVRAS-CHAVE: Amor; Insólito; Sonho.

\begin{abstract}
This paper intents to analyze the importance of space in the construction of meanings in the fantastic narrative, taking as an example the Dream tale by Caio Fernando Abreu. From the analysis of this tale, we can see how the author brings to his text issues that affect the postmodern subject, especially those related to human relations often marked by fragile and inconsistent ties. Thus, in this narrative the fantastic and the unusual act to represent everyday reality and the fragility of human relations. Our theoretical support will be developed from the ideas of Roas (2012), Ceserani (2006), Gama-Khalil (2012), Borges Filho (2007), Brandão (2013), among others.
\end{abstract}

KEYWORDS: Dream; Love; Unusual.

INAUDITO

o que busco

entre abismos e cascalhos

é o imanente ritmo

na linguagem muda em vídeo-vida água queimando fogo [...]

\footnotetext{
${ }^{1}$ Doutoranda no Programa de Pós-Graduação em Letras (PPGL) da Universidade do Estado do Rio Grande do Norte (UERN), Professora do Instituto Federal do Maranhão (IFMA), Campus Pedreiras. livia.soares@ifma.edu.br

2 Pós-Doutora em Letras pela Universidade de Coimbra, em Portugal. Doutora em Letras pela Universidade de São Paulo (USP). Professora na Universidade do Estado do Rio Grande do Norte (UERN). marlymouras@uol.com.br
} 
o que busco

em minha reza onírica

está no nome

e é nômade

- o inaudito dito.

(Salgado Maranhão - Os arcos e a lira)

\section{NO COMEÇO, ERA UM SONHO...}

Conforme poema em epígrafe, o ser humano sempre sonhou decifrar seus mistérios íntimos em espaços diversos. Aliás, a experiência humana é marcada pela permanente busca (alimento, cura, felicidade, realização, conforto, completude, autoconhecimento). Nesse viés, "há um código imaginário inerente à espécie humana, que garante a sua perenidade" (ELIADE, 1972).

A esse respeito, importantes estudos auxiliam na tarefa de compreender a relação entre os sonhos, o imaginário, a consciência e seus símbolos. Os mais significativos foram desenvolvidos por Carl Gustav Jung, Sigmund Freud, Gilbert Durand e Marie Von-Franz. A partir deles, passou-se a compreender que as imagens presentes na linguagem são repletas de símbolos. Assim, "uma palavra ou imagem é simbólica quando implica alguma coisa além de seu significado manifesto imediato. Quando a mente explora um símbolo, é conduzida a ideias que estão fora da nossa razão" (JUNG, 1964, p. 16).

Freud, em seu primeiro livro, “A interpretação dos sonhos" (1900), apresentava o método de relato e interpretação onírica como meio mais eficiente de acesso ao inconsciente, a partir de indagações sobre por que ocorrem os sonhos, como eles funcionam e a relação deles com este nosso lado oculto.

Nesse ínterim, é importante considerar que ler uma obra de ficção também significa viver outra vida, a partir do inconsciente que se materializa, já que "a literatura ultrapassa o mundo real que incorpora" (ISER apud ROCHA, 1999, p. 66). Para Iser, o ato de criar ficções é inerente à condição humana e essa encenação pode ser considerada uma condição transcendental que permite perceber algo de intangível, propiciando, ao mesmo tempo, a experiência de alguma coisa que não se pode conhecer. Sobre a relação entre o literário, o fictício e imaginário e o mundo empírico, o autor afirmava que:

Já que o fictício e o imaginário caracterizam disposições antropológicas, eles não se confinam à literatura, desempenhando 
igualmente um papel em nossa vida cotidiana. A especificidade da literatura, o traço que a distingue como meio consiste no fato de que é produzida mediante uma fusão do fictício e do imaginário. [...] Se ela emerge da interação de ambos é também porque nenhum dos dois pode ter seu fundamento definitivamente esclarecido (ISER apud ROCHA, 1999, p. 67).

Levando esses aspectos em consideração, Iser igualmente considera que as ficções literárias se caracterizam como uma travessia entre dois mundos que sempre inclui um mundo que foi ultrapassado e o mundo-alvo a que visa. Nos sonhos, ocorre processo semelhante, pois também apresenta uma estrutura duplicada. De acordo com a teoria junguiana, os símbolos são a linguagem dos sonhos. Além disso, a chave para a compreensão de um sonho é conhecimento do símbolo (VON-FRANZ, 1988).

Dessa forma, julgamos que a narrativa analisada neste estudo estimula reflexões relacionadas a esses dois campos de atuação do inconsciente: o sonho e a literatura. Ambos despertam, a partir do espaço representado, análises sobre a transposição entre real e irreal e a constituição identitária dos indivíduos frente às imagens que esses constroem a partir de suas experiências.

E como foco desta análise, considera-se o espaço como um importante componente para a construção de sentidos e, na narrativa fantástica, é fator decisivo na interpretação das simbologias geradas pela linguagem polissêmica. A seleção de determinada espacialidade impera na geração de sentidos e enfatiza o efeito de mistério, imprecisão, isolamento, medo, imprimindo sugestão ao texto, oferecendo "pistas" para sua recepção.

A descrição do espaço é um dos efeitos da superação de fronteiras entre o real e o irreal, além de ser um dos elementos deflagradores da ambiguidade, que por sua vez resulta na hesitação, que, conforme Todorov (2004), é um dos fatores que desencadeiam o fantástico. $\mathrm{O}$ autor também enfatiza que é na literatura fantástica que ocorre a interpenetração entre o mundo físico e o espiritual. Para Ceserani (2006, p. 83) "os textos fantásticos agridem a unidade da subjetividade e da personalidade humana, procuram deslocá-la e colocá-la em crise; eles rompem a relação orgânica (psicossomática) entre espírito e corpo".

Na narrativa, os espaços são marcados pela transposição do espaço íntimo, que aparece como lugar do impossível e da repercussão dos dilemas e interdições sofridas socialmente. Essa mudança de visão se dá frente ao sonho em que a personagem principal tem durante algumas noites. No plano irreal ela se sente realizada após manter 
um relacionamento com um homem que ela diz amar e afirma ser correspondida, em um jogo entre realidade/lucidez e sonho/loucura. Sua vida passa a ter um propósito: reencontrar no mundo "real" o amor que ela tem certeza de existir. Estas diferentes espacialidades dão o mote à narrativa. Sobre essa relação do espaço e as ações insólitas, a pesquisadora Marisa Martins Gama-Kalil afirma que:

\begin{abstract}
A importância das espacialidades ficcionais não se encerra apenas na caracterização da paisagem geográfica ou da caracterização das personagens ou caracterização das paisagens geográficas, como um mero pano de fundo, porém pode ser entendida como uma forma de revelar metaforicamente as práticas ideológicas do mundo posto em ficção e ser um potente canal de deflagração dos sentidos, contribuindo para o desdobramento múltiplo da polissemia literária (GAMA-KHALIL, 2012, p. 30).
\end{abstract}

De acordo com o supramencionado, cada elemento da linguagem só tem sentido em uma rede sincrônica. Cada expressão é definida por referência a um quadro ou paradigma. Bachelard em "A poética do espaço" defendia a importância de "tomar o espaço como análise para a alma humana" (2005, p. 20). Através dele se pode chegar a uma fenomenologia da imaginação, por essa razão, a imagem poética tem um mecanismo próprio. Assim, define-se como "topoanálise" o estudo psicológico e sistemático dos locais de nossa vida íntima.

O espaço em que se instala um indivíduo possui papel determinante nas ações e modos de pensar, ou seja, o equilíbrio social e psicológico de um homem está ligado às situações e possibilidades do espaço onde ele projeta suas experiências e sentimentos. Para Foucault, "estamos em uma época em que o espaço se oferece a nós sob a forma de relações de posicionamentos" (FOUCAULT, 2009, p. 413).

Certos jogos de oposição como espaço privado e espaço público, espaço da família e espaço social, espaço da cultura e espaço do útil, espaço de lazer e espaço de trabalho, ainda são tidos como naturais (não criados). No fundo, o que estes jogos de oposição revelam são as relações que definem os posicionamentos, e o fato de que a análise destas relações poderia trazer à tona os elementos que, ainda, sacralizam o espaço e estruturam o mundo. Foucault se propõe a analisar um tipo especial de relação de posicionamento (de espaço), que tem a propriedade de estar em relação com todos os outros posicionamentos. Estes podem ser divididos em diferentes formas, entre elas a utopia e heterotopia. 
REVISTA X, Curitiba, volume 14, n.6,p. 143-156, 2019.

Foucault (2009) entende que as heterotopias estão em oposição às utopias, uma vez que são lugares que são delineados na própria instituição da sociedade, e que são espécies de contra posicionamentos, espécies de utopias efetivamente realizadas e todos os outros posicionamentos reais que se podem encontrar no interior da cultura estão ao mesmo tempo representados, contestados e invertidos, espécies de lugares que estão fora de todos os lugares, embora eles sejam efetivamente localizáveis (FOUCAULT, 2009).

Oziris Borges Filho em "Espaço e literatura: introdução à topoanálise" (2007) repercute essa questão relacionando essa transposição do espaço íntimo em diversos planos também por meio de inferências sociológicas, filosóficas e estruturais. Para o autor, todas elas fazem parte de uma interpretação do espaço na obra literária.

Topoanálise é o estudo psicológico que abarca também todas as outras abordagens sobre espaço. Assim, as interferências sociológicas, filosóficas e estruturais fazem parte de uma interpretação do espaço na obra literária (BORGES FILHO, 2007, p. 33). Isso comprova que assim quanto qualquer outro elemento da tessitura da narrativa, o espaço, especialmente no conto fantástico, aciona a engrenagem e dá pistas sobre a interpretação dos símbolos e elipses.

Brandão (2007) define quatro modos de definição do espaço na literatura. São eles: representação do espaço; espaço como forma de estruturação textual; espaço como focalização; espaço da linguagem. Segundo o autor, o primeiro modo, provavelmente o mais recorrente, é o que se interessa pela representação do espaço no texto literário. Nesse tipo de abordagem, nem se chega a indagar o que é espaço, pois este é dado como categoria existente no universo extratextual. Isso ocorre, sobretudo, nas tendências naturalizantes, as quais atribuem ao espaço características físicas, concretas (aqui se entende espaço como "cenário", ou seja, lugares de pertencimento e/ou trânsito dos sujeitos ficcionais e recurso de contextualização da ação).

Dessa forma, o espaço novamente é reconhecido como fator desencadeador das ações, reverberando na forma como o enredo se organiza, e que também ajuda a delinear os descentramentos do sujeito, reverberando na arquitetura de sentidos que o leitor terá de decifrar. A esse respeito, Brandão reconhece que:

Nos Estudos Literários contemporâneos, a vertente mais difundida dessa tendência é, possivelmente, a que aborda a representação do "espaço urbano" no texto literário. Outra vertente bastante significativa é a que, com maior ou menor afinidade com os Estudos 
Culturais, utiliza um léxico espacial que inclui termos como margem, território, rede, fronteira, passagem, cartografia, buscando compreender os vários tipos de espaços representados no texto literário em função do fato de se vincularem a identidades sociais específicas (BRANDÃO, 2007, p. 208-209).

Essa característica é recorrente na narrativa de Caio Fernando Abreu, em que a sobreposição de planos, os efeitos insólitos e o condicionamento social e psicológico da personagem são engendrados numa atmosfera alucinante e desprovida de lógica. Temse assim a representação de identidades descentradas em lugares reais e os elementos insólitos traduzem uma das marcas do conto fantástico moderno ao fazer uso da fragmentação e de uma série de elementos descontínuos, resultando no desdobramento na atmosfera de incerteza e ambiguidade.

\section{ONÍRICO: ENTRE A REALIDADE E ATRANSGRESSÃO DAS LEIS LÓGICAS}

Caio Fernando Abreu nasceu em 1948 e faleceu em 1996. Foi um autor notadamente emblemático, com uma escrita inovadora e uma atuação artística marcante. É reconhecido por sua escrita irreverente, deu destaque à contracultura, à cultura de massa, à mistura de linguagens e além da influência de outras artes especialmente a música e o cinema. Sua escrita é marcada por uma confluência de tendências históricas, artísticas e sociais, somada às angústias trazidas pela modernidade, identidades em trânsito, o mal-estar trazido pela mecanização dos meios de produção.

A obra "Ovelhas negras" é uma antologia de contos selecionados ao longo da atuação literária de Abreu. Na introdução da obra o autor descreve como o livro nasceu:

Nunca pertenci àquele tipo histérico de escritor que rasga e joga fora. Ao contrário, guardo sempre as várias versões de um texto, da frase em guardanapo de bar à impressão no computador. Graças a essa obsessão é que nasceu "Ovelhas negras", livro que se fez por si durante trinta e três anos (ABREU, 2018, p. 532).

O conto Onírico inicia a partir da revelação do sonho de uma mulher sem nome: "Veio num sonho certa noite. Ela o amava. Ele a amava também. E ainda que essa coisa, o amor, fosse complicada demais para compreender e detalhar nas maneiras tortuosas como acontece, naquele momento em que acontecia dentro do sonho, era simples [...] dormiam juntos, no sonho, porque era bom para um e para o outro estarem assim juntos, naquele outro espaço" (ABREU, 2018, p. 660). 
"Dentro do sonho" se configura como um espaço distinto da realidade almejada pela personagem. Para Jung (2000) o sonho é sempre um despertar do inconsciente em que formas que não foram conscientes acabam por emergir. A psique humana é constituída por dois polos divergentes, o consciente e o inconsciente. À consciência pertence a moral convencional, o intelecto, o medir e quantificar, a motivação pra alcançar um ideal e o senso de planejamento para concretizá-lo. Apesar de voltada para a realidade, a consciência a capta de maneira fragmentada, de trecho em trecho. A consciência tem um centro: o "eu" autorreflexivo.

Esse confronto de imagens entre os planos do sonho e da realidade no universo é amplamente explorado: "Coisas assim, ela via. E de olhos abertos, embora fechados, pois sonhava, protegia-o, protegiam-se no meio da noite. Tão simples, tão claro. E de alguma forma inequívoca, para sempre" (ABREU, 2018, p. 660). Sobre esse aspecto, Brandão defende que esse posicionamento do narrador também ajuda na orientação dos sentidos da narrativa, conforme descrito a seguir:

Assim, o espaço se desdobra em espaço observado e espaço que torna
possível a observação. Observar pode equivaler a mimetizar o registro
de uma experiência perceptiva. Mas observar também pode equivaler,
bem mais genericamente, a configurar um campo de referências do
qual o agente configurador se destaca (o que justifica que se enfatize,
por exemplo, ao autor reflexividade da voz poética) (BRANDÃO,
2007, p. 211).

A partir dessas ideias, infere-se que por meio da leitura de uma obra literária é possível conhecer novos espaços, contemplar novas experiências. No conto analisado, essa sobreposição de planos e ambientes contribui para a transição e o jogo entre sonho e realidade, que em muitos trechos se misturam. Essa sobreposição de planos contribui para que a atmosfera de incerteza e imprecisão se instaure.

A personagem buscava em homens "reais" a fisionomia que viu no sonho, seu cheiro, suas características. Antecipava a cada dia o horário do sono, intrigava-se e queria ter alguém com quem compartilhasse sua experiência amorosa, porém quando amanhecia, a mulher não tinha sequer alguém para telefonar e contar seu sonho. Torcia para que o sono logo chegasse para que pudesse ter a presença do rapaz que se envolveu, despistou compromissos e telefonemas, queria ficar dentro de si. Em meio à solidão, fumava no quarto escuro, pois sabia que de alguma forma ele estaria ali.

O enredo alude aspectos do imaginário a partir da sobreposição de planos e cenários, do sonho como refúgio e a ideia de aprisionamento do Eu, pois a realidade 
concreta não é capaz de proporcionar à mulher a felicidade de ter alguém a quem pudesse amar. A respeito disso, as considerações de Durand (1989) atestam que

É por ela [pela imaginação] que passa a doação do sentido e que funciona o processo de simbolização, é por ela que o pensamento do homem se desaliena dos objetos que a divertem, como os sonhos e os delírios que a pervertem e a engolem nos desejos tomados por realidade (DURAND, 1989, p. 37).

Conforme o supramencionado, é pela imaginação que é possível o equilíbrio psicossocial, por isso a imaginação suaviza a dureza das experiências concretas, especialmente em uma sociedade muitas vezes sistematizada por rótulos em que a solidão e a superficialidade se destacam. Desse modo, as figurações simbólicas são produzidas pelos desejos e impressões do sujeito que são resultados das acomodações afetivas individuais e a relação ao meio.

O narrador do conto esclarece que todas aquelas alucinações não passavam de mero artifício, pois sempre que a personagem dormia, o leitor pode ser estimulado a questionar se o homem realmente havia estado ali, mesmo ela sentindo seu cheiro. Essas sensações também podem ser mais uma alucinação da personagem, obcecada pelo desejo de ter alguém.

Em vários trechos o narrador desacredita das sensações e delírios da personagem, o que reforça que aquele sonho é mais um devaneio. Ao sair do universo onírico "eram vazias ela e as manhãs" (ABREU, 2018, p. 661). Após mais uma noite, a mulher procurou o telefone para contar às amigas: ninguém deu crédito, "isso deve ser falta de sexo" respondeu uma. Mesmo assim, sempre nutria a esperança de encontrá-lo "noutro espaço, num mundo paralelo, sim, poderia encontrá-lo numa interfrequência de rádio ou televisão, num reflexo do espelho" (ABREU, 2018, p. 662). Passou a esperar nas madrugadas acordada, olhando a TV, sem sucesso. Passou a frequentar shoppings e pizzarias, pois ele também poderia estar no mundo real, porém ele não estava em nenhum lugar que fosse.

O insólito surge por essa inquietude e sobreposição de espaços, a partir da fusão entre o espaço do sonho e o espaço "real". Para Todorov (2009), a sobreposição de dimensões permite a convergência de espaços díspares e dispersos. Os cenários realista e alucinante se intercambiam frequentemente. 
REVISTA X, Curitiba, volume 14, n.6,p. 143-156, 2019.

Nos dias seguintes, no fundo de um sonho, a personagem esperançava que poderia encontrá-lo. Passou a aspirar camisas abertas dos homens nos ônibus, nas filas, nos correios. "Dilatava as narinas em lugares públicos cheio de homens suados - mas nenhum cheiro era o dele" (ABREU, 2018, p. 662). Uma atmosfera de desesperança e frustração é representada a partir da sucessão de sentimentos, sem saber se o que ela procurava realmente havia acontecido:

Mas se passara tanto tempo desde aquela vez a original, a única, que não saberia mais se seria ainda uma memória ou sua primeira Invenção Desesperada. Insistia: cílios longos macios. Sem vírgulas longos macios os cílios do homem que ela amava e que ele amava também naquela noite e para sempre no meio de um sonho ficando antigo demais e meio disperso (ABREU, 2018, p. 662).

Conforme exposto, se verifica a atmosfera de incertezas diante do possível sonho que a levara a tão incessante busca, pois sua vida passa a ser motivada por "Invenções Desesperadas". O fluxo de consciência, típico das neuroses dos tempos atuais, a busca pela completude a partir do outro e a incerteza se aquela experiência realmente foi vivida ou não.

A personagem passou a fazer Íntimas Orgias Imaginárias. "Fossas nasais abertas onde ela passava a ponta da língua tentando identificar o cheiro e o gosto salgado do homem a quem rendera momentos de satisfação e prazer. Ambos se amavam e isso era pra sempre, apesar de fugaz" (ABREU, 2018, p. 663). Os antagonismos, reflexos dos paradoxos vividos pela personagem permitem a construção de uma atmosfera marcada pelo vazio, pelo efêmero, pelo instante inebriante e pela solidão.

Passou então a viver uma vida real-objetiva enquanto ele acontecia dentro de si, no outro espaço sem que ninguém soubesse, porém não encontrou o mesmo prazer "por trás do sonho, resistia o real impiedoso" (ABREU, 2018, p. 663), Mas “essa não era a forma ideal de procurá-lo" ratifica o narrador, que ironicamente "reprova" a forma como a personagem se esvazia em busca de um sonho.

Queria encontrar seu "príncipe" e, de forma obsessiva o chamava, tinha certeza de que estava dentro de si, porém nunca mais voltou a vê-lo, nem no sonho nem na vida. A transposição de planos (real/imaginário) é frequente, contrastando a realidade alienante à realidade imaginada e desejada, representada pelo sonho que se torna uma espécie de zona de evasão. Ao perceber que a busca não resultava em nenhum efeito 
prático, a personagem resolve recorrer a outras instâncias do imaginário, conforme descrito a seguir:

Busca passava por "inúteis cartomantes, trânsitos, runas, ebós. O Valente de Copas traria carta de amor assim que Netuno abandonasse a posição de Vênus na carta do Karma, Poerth anunciaria o reencontro das coisas pedidas se Oxum aceitasse as rosas amarelas jogadas na cachoeira. Nessa região movediça da qual não desacreditava de todo, pois, afinal, fora onde o conhecera - ele também não estava" (ABREU, 2018, p. 663).

A mulher desejava a todo custo reviver o que sonhara, a aparente obsessão se tornava cada vez mais concreta: o cheiro, a presença do homem que só aparecia do plano da irrealidade, mas estava convicta de que ele a amava, conforme descrito a seguir:

Quando eu voltar princesa e você gladiador entre feras, quem sabe na arena; quando emergir do fundo das águas para espiar teu reino terrestre e verde, à superfície, quando eu talvez sereia, mulhermaravilha, pastora e astronauta navegando em abismos - quem, quem sabe quando?" (ABREU, 2018, p. 664).

O universo onírico surge novamente, aproximando-se de discursos em que a fuga e o desejo de viver em uma realidade ideal é o principal objetivo, desejava tê-lo novamente em diversos lugares na arena, nas águas, no universo todo. Mas quando voltava à realidade concreta só sentia o cheiro do homem e a incompletude de sua ausência, esta era a única recordação que se agarrava. Cogitou se matar, "mas a vida era aqui e agora" (ABREU, 2018, p. 664).

A mulher teve outras experiências amorosas, mas aprendeu a ir dormir mais cedo que podia pois era no mundo do sonho que encontrava sentido para existir. Por mais que o tempo passasse, sempre recorria à memória e, recostada no ombro do amado, continuava eterno naquele segundo que o viu. Repetia sozinha "eu te amo" em uma atitude que beirava a obsessão.

Ao logo da narrativa o fantástico, o insólito, o inconsciente e o irreal se misturam ao plano "real", o sonho pressupõe imagens alocadas na memória e que por algum motivo vêm à tona. A esse respeito, Irene Bessière afirma:

O fantástico não é senão um dos métodos da imaginação, cuja fenomenologia semântica se relaciona tanto com a mitografia quanto com o religioso e a psicologia normal e patológica. E que, a partir disso, 
não se distingue daquelas manifestações aberrantes do imaginário ou de suas expressões codificadas na tradição popular (BESSIËRE, 2012, p. 02).

A autora ainda afirma que o relato fantástico utiliza marcos socioculturais e formas de compreensão que definem os domínios do natural e do sobrenatural, do banal e do estranho, não para concluir com alguma certeza metafísica, mas para organizar o confronto entre os elementos de uma civilização relativos aos fenômenos que escapam à economia do real e do surreal, cuja concepção varia conforme a época.

Há um certo índice de realidade imaginária. Confirmando as primeiras proposições de Todorov, Bessière considera que o fantástico instaura a desrazão na medida em que ultrapassa a ordem e a desordem, e o homem percebe a natureza e a sobrenatureza como marcas de uma racionalidade formal. O relato fantástico se materializa pelas contradições, hesitações e fraturas das convenções coletivas submetidas ao exame.

Alude-se também às concepções da psicanálise de Freud e a psicologia analítica de Jung, uma vez que o conteúdo do sonho direciona todo o enredo do conto. Constatou-se que por meio dos pensamentos oníricos latentes, ou seja, aquilo que corresponde aos traumas e desejos mais profundos, a protagonista passou a busca pelo que foi vivido no sonho. Para Freud, todo sonho tem um significado que se liga a uma realização de um desejo reprimido pela sua consciência. Normalmente esses desejos são primitivos e, portanto, essa repressão surge por serem desejos vetados pela moral vigente da cultura na qual o sujeito está inserido.

Considera-se ainda a simbologia presente nos lugares que a personagem percorreu para concretizar as visões do sonho. Sobre isso, Jung (1975, p. 98) afirma que “os sonhos são os melhores instrumentos para o estudo da própria essência do homem”. Dessa forma, o conto mesmo permeado de acontecimentos ilógicos e imprevisíveis representa imagens que são transportadas da esfera da realidade para a da mente. Dentro da mente estes fenômenos tornam-se acontecimentos psíquicos, por isso, acontecimentos aparentemente ignorados em algum momento podem eclodir no inconsciente e brotam como um segundo pensamento.

No desfecho do conto a personagem novamente embebia-se na inebriante experiência da busca "pouco antes de dissolver-se na espuma do sono, eu te amo. Mas se pudessem saber, os outros, todos saberiam que isso não deixa de ser uma vitória. 
REVISTA X, Curitiba, volume 14, n.6,p. 143-156, 2019.

Certa espécie de vitória, mas tão dúbia que parece também uma completa derrota" (ABREU, 2018, p. 664).

O final também apresenta simbologias, "a espuma do sono" remete ao final do conto "A pequena sereia" de Andresen, cuja personagem mergulhou na espuma do mar para reencontrar o homem amado que habitava no fundo do oceano. Assim como a sereia, a personagem do conto Onírico também se entregou em um espaço desconhecido visando viver um amor (im)possível. Constatou-se que o inconsciente, o duplo e o insólito reaparecem pois as imagens do sonho sobrepuseram à vazia realidade da mulher que sonhava amar e ser amada, por isso desejou dormir para sempre.

\section{CONSIDERAÇÕES FINAIS}

O espaço em Onírico é revelador de muitas mensagens e simbologias, é parte integrante dos acontecimentos e das peripécias ocorridas em torno da trama. Esses recursos assumem papel fundamental na trama, pois garantem ao enredo uma complementação nos sentidos do conto. As constantes sobreposições de espaços: o quarto escuro, os espaços públicos, o transporte coletivo, a TV, os terreiros e templos religiosos revelam a busca pela concretização das imagens vistas no sonho.

Os espaços percorridos pela personagem demonstram a incompletude e insatisfação com o mundo real e personificam as angústias percebidas na sociedade moderna. A mulher sem nome transita pela indigência de ter sonhado e recebido afeto, a busca pelo homem do sonho passa a ser seu propósito de uma possível felicidade demonstrando o vazio, falta de esperança e solidão, seus espaços íntimos passam a ser externados na vida concreta, confrontando loucura e lucidez, sonho e realidade.

Assim, com base nas considerações teóricas aqui apresentadas e na tessitura do texto podemos entender que o espaço não pode ser unicamente exterior pois é vivido, imaginado, recordado a todo instante. Verifica-se que o universo onírico age como fator desencadeador dos acontecimentos insólitos o que permite perceber a sobreposição de espaços utópicos e heterotópicos, de acordo com a visão de Foucault (2009).

Esses espaços construídos por onde a personagem passa e vive sua constante aflição e busca, criam de um modo subliminar as imagens que compõem um verdadeiro universo íntimo e psicológico da mulher. Desse modo, através das análises aqui discutidas a partir da narrativa de Onírico percebeu-se que espaço ficcional constitui-se como uma base por meio da qual o leitor será instigado a questionar sua realidade empírica a partir da sobreposição entre o real/possível e o irreal/insólito. 
REVISTA X, Curitiba, volume 14, n.6,p. 143-156, 2019.

Para finalizarmos, parafraseamos Antonio Cândido (2011), ao afirmar que a literatura sabe muito sobre os homens, percebe-se que a arte apesar de seu caráter criativo também pode apontar para análises sobre a evolução social e humana ocorrida nos últimos séculos, além de diversos deslocamentos (sociais, filosóficos, antropológicos etc) que emolduraram novos paradigmas comportamentais e questionamentos acerca das relações de poder. As alegorias produzidas a partir dos eventos insólitos e sobrenaturais repercutem em universos transitórios, colocam em xeque a ideia que o ser humano pode prever e dominar tudo e que os mistérios e o desconhecido ainda permitem muitas revelações e reflexões.

\section{REFERÊNCIAS}

ABREU, C. F. Contos completos. Rio de Janeiro: Companhia das Letras, 2018.

BACHELARD, G. A poética do espaço. São Paulo: Martins Fontes, 2005.

BESSIÉRE, I. O relato fantástico: forma mista e o caso da adivinha. Revista Fronteira $Z$, n. 9, Dezembro 2012.

BORGES FILHO, O. Espaço e Literatura: introdução à topoanálise. Franca: Ribeirão Gráfica e Editora, 2007.

BRANDÃO, L. A. Breve história do espaço na Teoria da Literatura. Cerrados. Brasília, UnB, n. 19, p. 115-133, 2005.

CALVINO, I. (Sel.). Contos fantásticos do século XIX: o fantástico visionário e o fantástico cotidiano. Vários tradutores. São Paulo: Companhia das Letras, 2011.

CÂNDIDO, A. Literatura e formação do homem. Ciência e cultura. São Paulo, v 24. n. 9, 2011.

CESERANI, R. O fantástico. Tradução de Nilton Cezar Tridapalli. Curitiba: Ed. UFPR, 2006.

DURAND, G. As estruturas antropológicas do imaginário. Lisboa: Presença, 1989.

ELIADE, M. Os mitos e os contos de fadas. In: ELIADE, M. Mito e realidade. São Paulo: Perspectiva, 1972. (Debates, 52). p. 167-175.

FOUCAULT, M. Ditos e Escritos vol. III. Estética: Literatura e Pintura, Música e Cinema. São Paulo: Forense Universitária, 2009.

FRANZ, M. L. V. O Caminho dos Sonhos. São Paulo: Editora Cultrix, 1988. 
GAMA-KHALIL, M. M. As teorias do fantástico e sua relação com a construção do espaço ficcional. In: GARCIA, F.; BATALHA, M. C. Vertentes teóricas e ficcionais do insólito. Rio de Janeiro: Editora Caetés, 2012.

JUNG, C. G. O homem à descoberta da sua alma. Porto: Brasília, 1975.

JUNG, C. G. Estudos de psicologia analítica. Petrópolis: Vozes, 1991.

JUNG, C. G. Os arquétipos e o inconsciente coletivo. Petrópolis: Vozes, 2000.

JUNG, C. G. Sonhos memórias reflexões. Rio de Janeiro: Nova Fronteira, 2015.

JUNG, C. G. et al. O homem e seus símbolos. Rio de Janeiro: Nova Fronteira, 1965.

MARANHÃO, S. In: Os Arcos e a Lira. Organizadores: Angela Melim, Carlos Lima e Renato Casimiro. Letras/UERJ, Rio de Janeiro, 1998.

ROAS, D. A ameaça do fantástico: aproximações teóricas. Trad. Julián Fuks. São Paulo: Unesp, 2014.

ROCHA, J. C. de C. (Org.) Teoria da ficção: indagações à obra de Wolfgang Iser. Rio de Janeiro: Eduerj, 1999.

TODOROV, T. Introdução à literatura fantástica. Trad. Maria Clara Correa Castello. São Paulo: Perspectiva, 2008. 